\title{
Response Surface Regression Model in Optimization of Alum Sludge Drying Facility: Solar-Fenton's Reagent Dewatering
}

\author{
Maha A. Tony and Aghareed A. Tayeb
}

\begin{abstract}
Sludge, is a by-product from the water works plants, has become a new challenge for the Egyptian government. In this study, a novel combination of chemical conditioning, Fenton's reagent, with the application of solar drying were examined. Evaporative solar dryer system has been installed on the sun-shine to convert alum sludge into a drier, through solar radiation exposure resulting in decreased moisture concentration. The experimental design methodology was applied to optimize the dewatering techniques using the solar-photo-Fenton's reagent. The variables considered were the $\mathrm{H}_{2} \mathrm{O}_{2}$ and $\mathrm{Fe}^{3+}$ concentrations and $\mathrm{pH}$ of the sludge. The experimental design allowed to develop the model for optimizing the reaction variables (after $3 \mathrm{~h}$ of reaction). Under the optimum conditions, $94 \%$ solids was experimentally reached. Both $\mathrm{H}_{2} \mathrm{O}_{2}$ and $\mathrm{Fe}^{3+}$ concentrations have an important effect in the dewatering. Solar sludge drying was proved to be efficient for regions which receive high annual solar radiation such as Egypt.
\end{abstract}

Index Terms-Alum sludge, drying, Fenton's reagent, response surface methodology, solar energy.

\section{INTRODUCTION}

A large quantity of sludge is generated each year from water treatment plants in Egypt. Aluminium sulphate is arguably the most widely used coagulant in that drinking water treatment plants. Disposing such sludge to the nearest watercourse is the common practice in Egypt, which accumulatively rise the aluminum concentrations in water and consequently in human bodies [1]. Traditionally, chemical conditioning is widely applied to improve the sludge dewaterability [2]-[6]. This includes the use of various organic polymers [7]-[9] and surfactants [10].

On the other hand, in recent years, advanced oxidation processes (AOPs) for sludge conditioning have been gaining increased global attention, Fenton's reagent [11]. This is due to the recognized potential of such processes and the perceived long term risks of polymer residual to environment. On the contrary, there is very little information found in the literature on the use of the Fenton's reagent for water treatment sludge conditioning. In our previous study, the effectiveness and optimization of Fenton's reagent for an alum sludge conditioning were preliminarily investigated

Manuscript received December 26, 2015; revised February 17, 2016. This work samples were supported from the Kedwan water treatment plant, Minia, Egypt, which is acknowledged.

M. A. Tony is with the Faculty of Engineering, Minofya University, Minofya, Egypt (e-mail: maha_tony1@ yahoo.com).

A. M. Tayeb is with Minia University, Faculty of Engineering, Minia, Egypt (e-mail: aghareed1@yahoo.com).
[12]-[14]. The addition of $\mathrm{Fe}^{2+} / \mathrm{H}_{2} \mathrm{O}_{2}$ led to a considerable improvement in the alum sludge dewaterability reached to $47 \%$ evaluated by the capillary suction time.

Over the last years, solar sludge drying has acquired significant interest. Sludge drying is, obviously, dewatering the sludge completely after dewatering. This usually involves sludge drying beds in a solar sludge drying process. In fact sludge drying is largely a process used in sewage treatment. Lower operating costs, and the heat needed for the drying process currently comes solely from the sun.

Factors to control the Fenton reaction process are the amounts of $\mathrm{Fe}^{2+}$ and $\mathrm{H}_{2} \mathrm{O}_{2}$. Optimising such amounts plays a key role towards the success of the Fenton process. A statistical-based technique commonly known as RSM (response surface methodology) [15] as a powerful experimental design tool has been increasingly applied in many fields including wastewater treatment and sludge pretreatment to study the optimization of the treatment process [16]-[18]. However, it has not been well exploited to optimize water treatment sludge conditioning using Fenton reagent according to the literature survey.

The intent of this study is to explore the use of Fenton's reagent as an alternative conditioner in the presence of solar energy using solar dryer. To achieve the maximum sludge drying rate RSM was applied to obtain the optimum Fenton's reagent parameters.

\section{MATERIALS AND METHODS}

\section{A. Materials}

Alum sludge samples (see Table I) used during this study were taken from a water treatment plant, Kedwan Station in Minia city, in the south of Egypt. In this station the treatment process uses aluminium sulfate to treat water taken from The River Nile.

TABLE I: PROPERTIES OF ALUM SLUDGE USED IN THIS STUDY SETTING

\begin{tabular}{cc}
\hline PARAMETERS, UNIT & VALUE \\
\hline SUSPEND SOLID (SS), MG/L & 2,364 \\
$\mathrm{PH}$ & 8.5 \\
SRF, M/KG & $2.24 \times 1013$ \\
TURBIDITY (SUPERNATANT), NTU & 274 \\
MOISTURE CONTENT, \% & 97 \\
\hline \hline
\end{tabular}

Fenton reagent, as the conditioner, are prepared by making 
a solution from $\mathrm{Fe}^{2+}$, namely, Ferrous Oxalate $\left(\mathrm{Fe}\left(\mathrm{C}_{2} \mathrm{O}_{4}\right)\right)$ and Commercial $\mathrm{H}_{2} \mathrm{O}_{2}$ (30\% by wt.) was used. $\mathrm{H}_{2} \mathrm{SO}_{4}$ and $\mathrm{NaOH}$ are used for $\mathrm{pH}$ adjustment of the sludge samples. All of those chemicals were supplied by Sigma-Aldrich.

\section{B. Low-Cost Solar Drier}

Fig. 1 shows the solar drier which consists of two parts: a flat plate collector, used as an air heater, and a drying chamber. The solar collector is a $300 \times 100 \mathrm{~cm}$ wooden box which is insulated at the top with a UV- stabilized glass cover and insulated. The solar collector is connected at its end to the drying chamber and at its front to the air blower, to provide air at the required flow rate. The drying chamber is fitted with trays for easy loading and unloading of the products to be dried.

The experimental setup is located at Minia City is $250 \mathrm{~km}$ south of Cairo city. The latitude and longitude of the location are between latitude $28^{\circ}$ and $28^{\circ} 40^{\prime} \mathrm{N}$ and longitudes $30^{\circ} 50^{\prime}$ and $31^{\circ} 30^{\prime} \mathrm{E}$ and $130 \mathrm{~m}$ above sea level, respectively. The region usually enjoys mild, sunny and dry seasons [19]-[21].

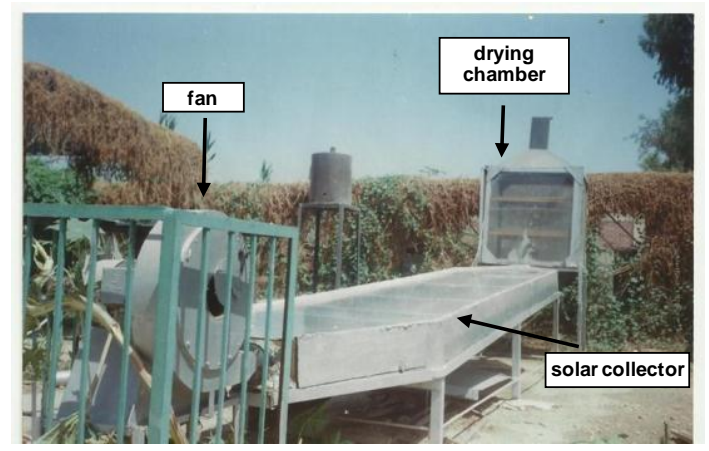

Fig. 1. Solar drying assisted system.

\section{Experimental Procedures}

On raw sludge with aid of solar energy in Solar dryer, solar energy can evaporate water on a set of preliminary experiments. In the main experiment done, Fenton reagent (Ferrous Oxalate and Hydrogen pyroxide) was used with the aid of solar energy.

The tests were carried out during the period of May 2013 to November. Experiments were started at $9.00 \mathrm{am}$ and continued till $8.00 \mathrm{pm}$. Intensity of solar radiation was measured by a solarimeter (Epply Black-and-White Solarimeter, Model 8-48). Hot wire anemometers (Airflow, Model TA5, accuracy $72 \%$ ) were employed to monitor the flow rate of the air passing through the air heater. Thermocouples were used to measure air temperatures in the collector, the air ducts and the drying chamber. The solar radiation in the site of the solar drying unit varied from 45 to $1014 \mathrm{~W} / \mathrm{m}^{2}$, while the ambient temperature is varied from 26 to $42^{\circ} \mathrm{C}$. Samples are left in the drying chamber until the desired moisture content $(\mathrm{y})$ is reached by using the following formula, [22]:

$$
y(w . b .) \%=\frac{\left(W_{1}-W_{2}\right)}{W_{1}} \times 100
$$

Electrical energy is used only to run the air blower for the object of supplying the air required for the drying process. An air velocity of $200 \mathrm{~m} / \mathrm{s}$ was found to be suitable for the drying unit under test.

Moreover, a Box-Behnken experimental design [15] was chosen to evaluate the combined effects of the three independent variables, i.e. $\mathrm{Fe}^{2+}$ dosing, $\mathrm{H}_{2} \mathrm{O}_{2}$ dosing and initial $\mathrm{pH}$ as $\alpha, \beta$ and $\gamma$ respectively, during the Fenton reagent conditioning.

\section{RESULTS AND DISCUSSION}

\section{A. Performance of Solar Dryer}

The performance of a dryer, or its drying efficiency, depends on the duration of the drying process and the quality of the end product. Besides, factors such as collector performance and drying temperature are to be taken into consideration. A detailed analysis of the performance of this dryer is being done. The no-load tests were conducted with the fan working at air flow rate of $200 \mathrm{~m} / \mathrm{s}$ and determining the hot air temperature at that condition. Solar radiation and temperature inside the collector were measured periodically along the day at time intervals of 15 minutes and the values are compared. During the drying operation the intensity of solar radiation fluctuates; leading to fluctuation in the temperature of air leaving the solar collector.

It is interested to note that the maximum rise in air temperature occurs shortly after solar noon, i.e., there is a time lag between the maximum value of solar intensity and the corresponding maximum value of the hot air. This is due to the thermal energy stored in the solar collector as sensible heat and which is given up by the collector to the air during its passage through the collector. The same explanation is given for the rise of air temperature above ambient by the end of the sunny day whilst the solar intensity is approaching zero at sunset. This is good because it extends the time of operation of the solar dryer for a couple of hours even after sunset.

\section{B. Experimental Design}

Box-Behnken design [15], which is the standard of RSM was selected for optimization. This factorial design was employed to fit the second-order polynomial models and. For statistical calculations, the three independent variables, i.e. initial $\mathrm{Fe}^{2+}, \mathrm{H}_{2} \mathrm{O}_{2}$ and $\mathrm{pH}$, were coded as $\alpha, \beta$, $\gamma$, respectively and their ranges and levels are presented in Table II.

TABLE II: RANGE AND LEVELS OF THE INDEPENDENT VARIABLES

\begin{tabular}{lccc}
\hline \multirow{2}{*}{ Variable } & \multicolumn{3}{c}{ Range and levels } \\
\cline { 2 - 4 } & -1 & 0 & 1 \\
\hline$\alpha$, initial $\mathrm{Fe}^{2+}(\mathrm{mg} / \mathrm{l})$ & 40 & 70 & 100 \\
$\beta$, inital $\mathrm{H}_{2} \mathrm{O}_{2}(\mathrm{mg} / \mathrm{l})$ & 200 & 500 & 800 \\
$\gamma, \mathrm{pH}$ & 2.0 & 5.0 & 8.0 \\
\hline \hline
\end{tabular}

\section{Solar Sludge Drying with Fenton Reagent}

According to the preliminary experiments, the economical reaction time of drying is reached after $3 \mathrm{~h}$. Values in Table II were converted to coded $(-1,0,1)$ values and a set of experiments was conducted according to SAS software (The experimental design is shown in Table III). 


$$
\begin{aligned}
y= & 89.54-1.23 \alpha+0.45 \beta-0.68 \gamma+1.14 \alpha^{2}-1.84 \alpha \beta \\
& -1.53 \alpha \gamma+1.15 \beta^{2}+0.54 \beta \gamma+1.29 \gamma^{2}
\end{aligned}
$$

The experiments are conducted in the solar dryer, then it is inserted to the software (SAS), so, the predicted values are given. In addition, the following second-order fitting polynomial equation was then obtained after the data fitting.

The average values of \%solids of the sludge obtained from the experiments and as the responses predicted via Eq. (2) are shown in Table III. It can be seen from Table III that a good agreement of the data between the experimental and the predicted is obtained. In addition, ANOVA analysis of the data showed that the regression coefficient $R^{2}$ value is reached to 0.96 . Thus, it is reasonable to believe that model is accepted as regression coefficient is more than 0.8 .

Thus, eq. (2) is used by software to get the optimum values: $\psi$ reached to $92.7 \%, \mathrm{Fe}^{2+}$ and $\mathrm{H}_{2} \mathrm{O}_{2}$ are 40 and $610 \mathrm{mg} / \mathrm{l}$, respectively and $\mathrm{pH} 7$. Thereafter, those values were used to conduct an experiment and the moisture content reduction is in a good agreement with the predicted one which is 94 .

TABLE III: FACTORS AND LEVELS OF BOX-BEHNKEN DESIGN FOR RSM

\begin{tabular}{|c|c|c|c|c|c|}
\hline \multirow[t]{2}{*}{$\begin{array}{l}\text { Run } \\
\text { no. }\end{array}$} & \multicolumn{3}{|c|}{ Coded factors } & \multicolumn{2}{|c|}{ Response (y, \%) } \\
\hline & & $\beta$ & $\gamma$ & Experimental & Predicted \\
\hline 1 & -1 & -1 & 0 & 91.50 & 90.71 \\
\hline 2 & -1 & 1 & 0 & 95.51 & 95.30 \\
\hline 3 & 1 & -1 & 0 & 91.87 & 91.99 \\
\hline 4 & 1 & 1 & 0 & 88.49 & 89.22 \\
\hline 5 & 0 & -1 & -1 & 92.47 & 92.75 \\
\hline 6 & 0 & -1 & 1 & 90.03 & 90.29 \\
\hline 7 & 0 & 1 & -1 & 92.87 & 92.56 \\
\hline 8 & 0 & 1 & 1 & 92.63 & 92.29 \\
\hline 9 & -1 & 0 & -1 & 91.96 & 92.29 \\
\hline 10 & 1 & 0 & -1 & 93.4 & 92.96 \\
\hline 11 & -1 & 0 & 1 & 93.64 & 94.00 \\
\hline 12 & 1 & 0 & 1 & 88.94 & 88.53 \\
\hline 13 & 0 & 0 & 0 & 89.44 & 89.54 \\
\hline 14 & 0 & 0 & 0 & 89.50 & 89.54 \\
\hline 15 & 0 & 0 & 0 & 89.70 & 89.54 \\
\hline
\end{tabular}
AND THE PREDICTED AND EXPERIMENTALLY REDUCTION EFFICIENCIES

Further illustrations between two different independent factors are illustrated as shown in Fig. 2-Fig. 4.

Solar Fenton's dewatering/conditioning indicated that the number and size of alum sludge flocks decreased by the solar photo-Fenton reaction. This is consistent with the observation for the sludge minimization by Fenton's reagent [12]. The dewatering is carried out when the $\cdot \mathrm{OH}$ radicals produced by photo-Fenton reaction attacked the sludge and broke up the sludge flocs. During the sludge dewatering, $\mathrm{H}_{2} \mathrm{O}_{2}$ was consumed by the photo-Fenton reaction. Therefore $\mathrm{H}_{2} \mathrm{O}_{2}$ continuously decreased with time. Dissolved total $\mathrm{Fe}$ ion $\left(\mathrm{Fe}^{2+}\right.$ plus $\left.\mathrm{Fe}^{3+}\right)$ concentration in the sludge rapidly decreased just after the initiation of the photo-Fenton reaction and was rather little during the photo- Fenton reaction. It might be due to that most Fe ions were entrapped to the sludge.
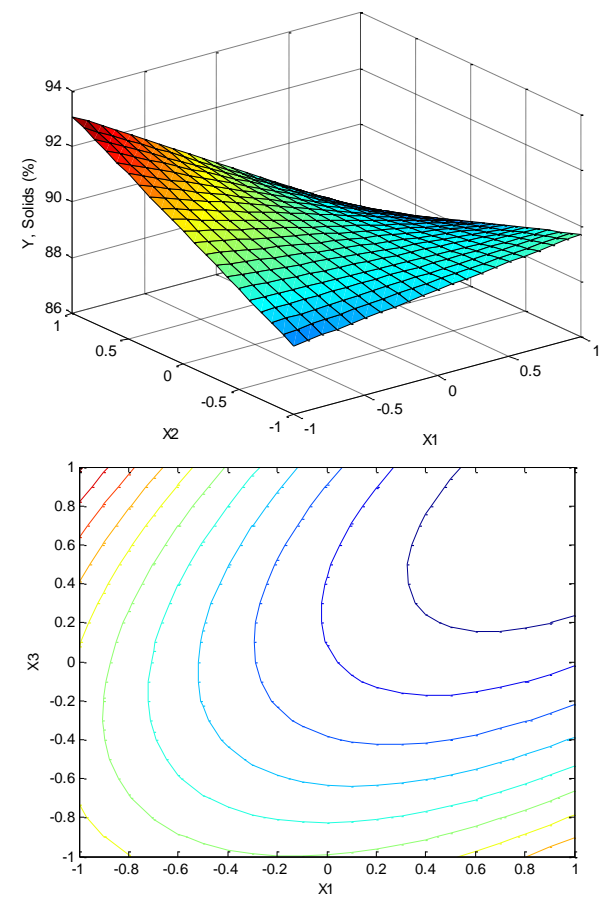

Fig. 2. Response surface and contour plot for alum sludge dewatering: $\mathrm{X} 1$ :coded $\mathrm{Fe}_{2+}$ and $\mathrm{X} 2: \mathrm{H}_{2} \mathrm{O}_{2}$ vs. predicted \%M.C.
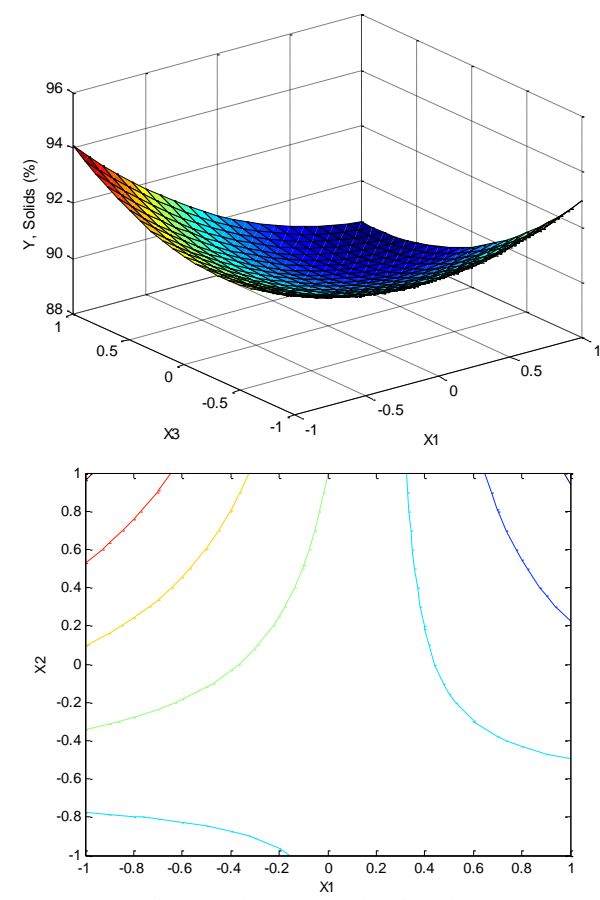

Fig. 3. Response surface and contour plot for alum sludge dewatering: $\mathrm{X} 1$ :coded $\mathrm{Fe}^{2+}$ and $\mathrm{X} 3: \mathrm{pH}$ vs. predicted \%M.C.

As shown in Fig. 2-Fig. 4, it is known that sub-optimal $\mathrm{pH}$ can decrease the amount of hydroxyl radicals, which is supposed to be the driving force towards the development the sludge dewatering [23]. An improved \%M.C. reduction is observed when $\left[\mathrm{Fe}^{2+}\right]$ increased. However, an increase in $\left[\mathrm{Fe}^{2+}\right]$ beyond the optimum region resulted in decreasing the \%M.C. reduction. This is mainly due to the fact that the excess of $\mathrm{Fe}^{2+}$ could negatively affect the coagulation-flocculation process and scavenges hydroxyl radicals generated through the reaction of Fenton's reagents.

The response surface as a function of the factors initial $\mathrm{pH}$ and $\left[\mathrm{H}_{2} \mathrm{O}_{2}\right]$ is shown in Fig. 4. At a high initial pH, the \% M.C. reduction increased dramatically with increased $\left[\mathrm{H}_{2} \mathrm{O}_{2}\right]$. This 
finding indicates that the interaction between initial $\mathrm{pH}$ and $\left[\mathrm{H}_{2} \mathrm{O}_{2}\right]$ is obvious. Such a finding is available in the literature confirming this [12].
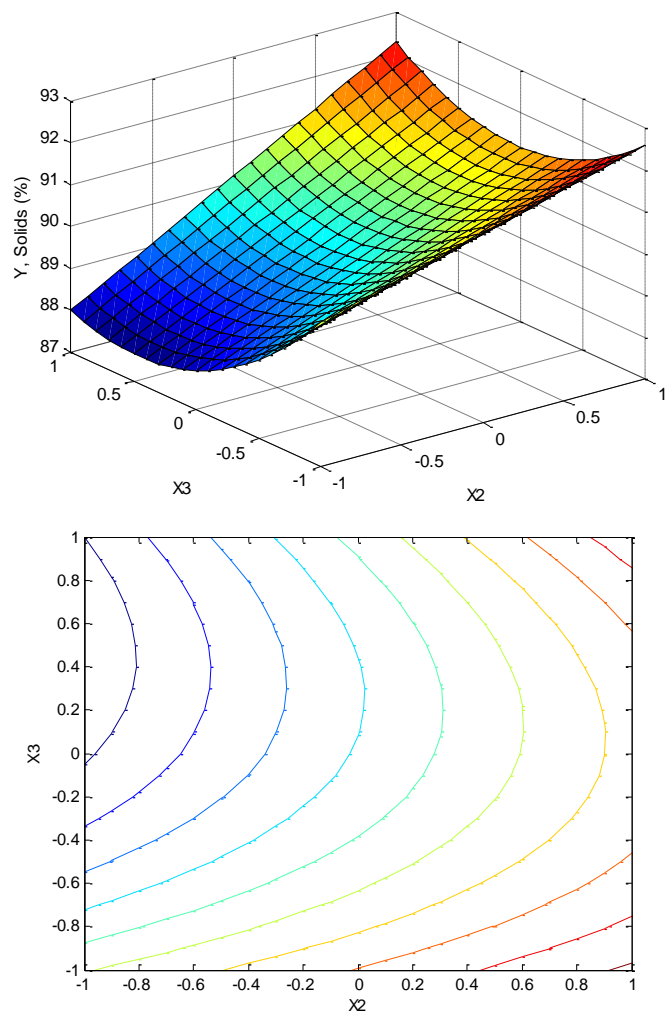

Fig. 4. Response surface and contour plot for alum sludge dewatering: $\mathrm{X} 2$ : coded $\mathrm{H}_{2} \mathrm{O}_{2}$ and $\mathrm{X} 3$ : $\mathrm{pH}$ vs. \%M.C.

\section{CONCLUSION}

Using free solar energy for water works alum sludge drying can be benefit in point of view of energy consumption and in consequence on the cost of the drying system. Fenton's reagent was added in order to increase the efficiency of the drying systems. According to the obtained results and the optimum conditions of the system by applying response surface methodology.

\section{ACKNOWLEDGMENT}

The authors would like to thank the water treatment plant in kedwan WWP, in El-Minia City, in the south of Egypt for providing the sludge samples.

\section{REFERENCES}

[1] M. O. Ramadan, H. A. Fouad, and A. M. J. Hassanain, "Reuse of wate treatment sludge plant in brick manufacturing," Applied Sci. Res., vol. 4, no. 10 , pp. 1223-1229, 2008.

[2] C. H. Lee and J. C. Liu, "Enhanced sludge dewatering by dual polyelectrolytes conditioning," Water Res., vol. 34, pp. 4430-4436, 2000.

[3] C. C. Wu, J. J. Wu, and R. Y. Huang, "Effect of floc strength on sludge dewatering by vacuum filtration," Colloids Surf., vol. A221, pp. 141-147, 2003.

[4] D. H. Bache and R. Gregory, Flocs in Water Treatment, IWA Publishing, London, 2007.

[5] H. Saveyn, D. Curvers, O. Thas, and P. Van der Meeren, "Optimization of sewage sludge conditioning and pressure dewatering by statistical modeling," Water Res., vol. 42, no. 4-5, pp. 1061-1074, 2008.

[6] Q. Yu, H. Lei, G. Yu, X. Feng, Z. Li, and Z. Wu, "Influences of microwave irradiation on sludge dewaterability," Chem. Eng. J., vol. 155 , pp. 88-93, 2009.
[7] Y. Q. Zhao and D. H. Bache, "Integrated effects of applied pressure, time, and polymer doses on alum sludge dewatering behaviour," Waste Manage, vol. 22, pp. 813-819, 2002.

[8] Y. Q. Zhao, "Enhancement of alum sludge dewatering capacity by using gypsum as skeleton," Colloids Surf., vol. A211, pp. 205-212, 2002.

[9] W. Ma, Y. Q. Zhao, and P. A. Kearney, "A study of dual polymer conditioning of aluminum-based drinking water treatment residual," $J$. Environ. Sci. Health A, vol. 42, pp. 961-968, 2007.

[10] C. Huang, J. R. Pan, C. G. Fu, and C. C. Wu, "Effects of surfactant addition on dewatering of alum sludge," J. Environ. Eng., vol. 128, no. 12, pp. 1121-1127, 2002.

[11] J. H. Kwon, K. Y. Park, J. H. Park, S. H. Lee, and K. H. Ahn, “Acidic and hydrogen peroxide treatment of polyaluminum chloride (PACL) sludge from water treatment.,"Water Sci.Techno., vol. 50, no. 9, pp. 99-105, 2004.

[12] M. A. Tony, Y. Q. Zhao, J. F. Fu, and A. M. Tayeb, "Conditioning of aluminium based water treatment sludge with Fenton's reagent: Effectiveness and optimising study to improve dewaterability," Chemosphere, vol. 72, pp. 673-677, 2008.

[13] M. A. Tony, Y. Q. Zhao, and A. M. Tayeb, "Exploitation of Fenton and Fenton-like reagents as alternative conditioners for alum sludge conditioning," J. Environ. Sci., vol. 21, no. 1, pp. 101-105, 2009.

[14] M. A. Tony, Y. Q. Zhao, and M. F. El-Sherbiney, "Fenton and Fenton-like AOPs for alum sludge conditioning: effectivness comparison with different $\mathrm{Fe}^{2+}$ and $\mathrm{Fe}^{3+}$ salts," Chem. Eng. Comm., vol. 198, pp. 442-452, 2011.

[15] D. C. Montgomery, Design and Analysis of Experiment, 1991, John Wiley, New York.

[16] SAS, SAS /STAT User's Guide. SAS Institute, 1990, Inc., Cary, NC.

[17] F. Torrades, M. Perez, H. D. Mansilla, and J. Peral, "Experimental design of Fenton and photo-Fenton reactions for the treatment of cellulose bleaching effluents," Chemosphere, vol. 53, pp. 1211-1220, 2003.

[18] C. T. Benatti, C. R. G. Tavares, and T. A. Guedes, "Optimization of Fenton's oxidation of chemical laboratory wastewaters using the response surface methodology," J. Environ. Manage, vol. 80, pp. 66-74, 2006.

[19] P. A. Vesilind, "The role of water in sludge dewatering," Water. Environ. Res., vol. 66, pp. 4-11, 1994.

[20] S. Abdel Twab, "Geotechnical evaluation of Minia-Maghagha Area, upper Egypt,” J. King Abdulaziz Univ.: Earth Science, vol. 7, pp. 143-157, 1994.

[21] M. H. Aly, J. R. Giardino, and A. G. Klein, "Suitability assessment for New Minia City, Egypt: A GIS approach to engineering geology,' Eviron. Eng. Geoscience, vol. 11, pp. 259-269, 2005.

[22] S. Ranganna, Manual of analysis of fruit and vegetable products, Tata McGraw Hill Publishing Company Ltd., New Delhi., 1996, ch. 9-13, pp. 94-95.

[23] M. C. Lu, C. J. Lin, C. H. Liao, R. Y. Huang, and W. P. Ting, "Dewatering of activated sludge by Fenton's reagent," Adv. Environ. Res., vol. 7, pp. 667-670, 2003.

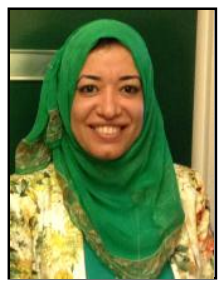

Maha A. Tony was born in El-Minia city in Egypt. She was graduated from Chemical Engineering Department, Faculty of Engineering, Minia University in 2002 Thereafter, she got her master degree in chemical engineering from that University in 2005. In 2009 got her Ph.D. through the channel scheme system between Minia University and University College Dublin, Ireland. She worked in wastewater treatment, the uses and applications of solar energy, waste minimizing, green chemistry, preparation of nano-materilas specially Starbons $®$.

She was a demonstrator in the faculty of engineering, Minofya university, Egypt from 2003 to 2005. Thereafter, from 2005 to 2007 she was Assistan Lecturer in the same faculty. In 2007 to 2009 she is nominated as a Ph.D. student in UCD, University College Dublin, Ireland. From 2009 to 2013 she worked as Lecturer of Chemical Engineering in Basics Science of Engineering Department, Faculty of Engineering, Minofya University, Egypt. In 2013 she worked as a staff associate researcher in the University of York, United Kingdom. In 2014 she was again a lecturer of chemical engineering in in Basics Science of Engineering Department, Faculty of Engineering, Minofya University, Egypt. From 2015 until now she is Associate Professor of Chemical Engineering in the same department. She has more than 30 publications in international journals and international conferences. Her research interests is dealing with sludge minimizing and conditioning, solar energy for waste minimizing such as wastewater 
treatment and industrial and agriculture waste drying facilities, design of solar energy equipment for waste water treatment, desalination and drying, modeling the experimental variables, preparation of Starbons ${ }^{\circledR}$ nano-materials, applications of the nano-materials in domestic and industrial wastewaters and the use of photo-catalysis for the treatment.

Dr. Tony is a member in the Society of Egyptian Engineers, member in woman network in Arab Science and Technology Foundation (ASTF) and Asia-Pacific Chemical, Biological \& Environmental Engineering Society (APCBEES). Dr. Tony was awareded in 2007 for a Ph.D mission from the Ministry of Higher Education in Egypt to study her Ph.D., in 2013 she was awarded a post doctoral fellowship to the University of York, York United Kingdom funded from the Ministry of Higher Education in Egypt.

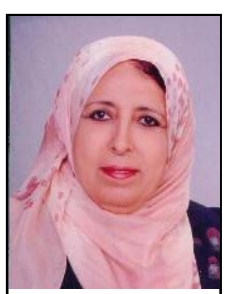

Aghareed M. Tayeb was born in Alexandria, Egypt. She was graduated from Chemical Engineering Department, University of Alexandria, Egypt in 1971. Thereafter, she got her master degree in 1978 from Chemical Engineering Department, University of Alexandria, Egypt. In 1981 she got her Ph. D. in chemical engineering and channel system, from University of Miami, USA and Minia University, Minia, Egypt respectively. She worked in solar energy applications a nd wastewater treatment.

She is a professor of chemical engineering in Minia University. She was formerly the dean of that faculty until 2008. From 2002 to 2005 she was the vice dean of the faculty. She got the positions as a lecturing assistant to a professor in Minia University in Faculty of Engineering from 1978 until now. From 1972 to 1978 she worked as an engineer in Moharrem Press, Alexandria, Egypt. She published one book, Renewable Energy; Sources and Conservation (Minia, Egypt: Minia university published online, Aghareed M.Tayeb, 2012). She has more than 90 articles published in international conferences or journals in the area of energy conservation, waste minimizing, water and wastewater treatment. Currently, she is dealing with solar energy storage, recycling of solid wastes, wastewater treatment, reuse of industrial wastes, solar drying, solar desalination, energy storage, simulation and modeling, ethanol production from agricultural wastes, energy conservation and recovery.

Prof. Tayeb is also a member in different memberships in professional societies, i.e. International Solar Energy Society, ISES \& American Solar Energy society ASES, international Energy Foundation IEF, Tripoli, Society of Egyptian Engineers, New York Academy of Sciences, National Council of Woman Affairs, Minia Governorate and Third World Organization for Women in Science, TWOWS. She has received an award from Minia University for being selected for the university prize of excellence for the year 2014. In 2006 she has been nominated from Minia Governorate as a member in the United Nation Development Program, UNDP, for the Slum Upgrading Project. She has registered for and got a patent on Production of a Biodegradable Plastic from Agricultural Wastes, Patent No. 13112002 , awarded from Egyptian Association for Social \& Technological developing designs for solar energy utilization in different fields, 1987. She received scholarship from University of Miami, Fla., USA, 1979, for completing her $\mathrm{Ph}$.D. study and completing a scientist technical program. 